\title{
PENGARUH PEMBERIAN CAP TIKUS TERHADAP KUALITAS SPERMATOZOA WISTAR JANTAN (Rattus norvegicus)
}

\author{
${ }^{1}$ Ellen E. Melmambessy \\ ${ }^{2}$ Lydia Tendean \\ ${ }^{2}$ Janette M. Rumbajan
}

\author{
${ }^{1}$ Kandidat Skripsi Fakultas Kedokteran Universitas Sam Ratulangi Manado \\ ${ }^{2}$ Bagian Biologi Fakultas Kedokteran Universitas Sam Ratulangi, Manado \\ Email: Elleneveline@ymail.com
}

\begin{abstract}
Alcohol is an organic compound that is composed of the elements carbon, hydrogen and oxygen. Usually, the term of alcohol is known as liquor. One of the local products of liquor in Manado is Cap Tikus. This study aims to determine the effect of alcohol $20 \%$ on the spermatozoa quality of male Wistar (Rattus norvegicus). The research design was a completely randomized experimental design. The samples were 10 male wistar rats which consisted of 5 rats as a control group and 5 rats as the experiment group. The rats in the experiment group were given Cap Tikus for 52 days, while rats in the control group were given tap water. The results showed that spermatozoa quality from experiment group which includes the concentration of spermatozoa is $24 \times 10^{6}$ spermatozoa/ml, normal motility of spermatozoa is $23,5 \%$ and normal morphology of spermatozoa is $11 \%$. Whereas spermatozoa quality from control group which includes the concentration of spermatozoa is $59 \times 10^{6}$ spermatozoa/ml, normal motility of spermatozoa is $89 \%$ and normal morphology of spermatozoa is $97 \%$. Conclusion: Cap Tikus decreased the spermatozoa quality which includes concentration, motility and morphology of spermatozoa. This was due to alcohol interfered the hypothalamus, the anterior pituitary gland and the testes that played an important role in the process of spermatogenesis.
\end{abstract}

Keywords: cap tikus, alcohol, spermatozoa quality

\begin{abstract}
Abstrak: Alkohol merupakan suatu senyawa organik yang tersusun dari unsur-unsur karbon, hidrogen dan oksigen. Dalam kehidupan sehari-hari, istilah alkohol sering dikaitkan dengan minuman keras. Salah satu jenis minuman keras produk lokal di Manado adalah Cap Tikus. Penelitian ini bertujuan untuk mengetahui pengaruh pemberian Cap Tikus terhadap kualitas spermatozoa wistar jantan (Rattus norvegicus). Desain penelitian yang digunakan adalah eksperimental dengan rancangan acak lengkap. Sampel adalah tikus wistar jantan berjumlah 10 ekor, 5 ekor tikus digunakan sebagaikontrol dan 5 ekor tikus digunakan sebagai perlakuan. Kelompok perlakuan adalah kelompok yang diberi minuman Cap Tikus selama 52 hari sedangkan kelompok kontrol adalah kelompok yang diberi minuman air ledeng. Hasil penelitian menunjukan kualitas spermatozoa kelompok perlakuan yang meliputi konsentrasi spermatozoa adalah $24 \times 10^{6}$ spermatozoa/ml, motilitas spermatozoa normal adalah $23,5 \%$ dan morfologi spermatozoa normal adalah $11 \%$. Kualitas spermatozoa kelompok kontrol yang meliputi konsentrasi spermatozoa adalah $59 \times 10^{6}$ spermatozoa/ml, motilitas spermatozoa normal 89\% dan morfologi spermatozoa normal 97\%. Simpulan: Pemberian Cap Tikus menyebabkan penurunan kualitas spermatozoa yang meliputi konsentrasi, motilitas dan morfologi spermatozoa. Hal ini dapat disebabkan karena alkohol mengganggu hipotalamus, kelenjar hipofisis anterior dan testis yang berperan dalam proses spermatogenesis.
\end{abstract}

Kata kunci: cap tikus, alkohol, kualitas spermatozoa 
Alkohol merupakan suatu senyawa organik yang tersusun dari unsur-unsur karbon, hidrogen, dan oksigen. Ciri khas alkohol yaitu terdapatnya gugus -OH pada rantai karbon. Golongan alkohol yang sering kita jumpai ialah metanol, etanol, isopropanol dan istilah alkohol dalam kehidupan seharihari sering dikaitkan dengan minuman keras yang mengandung etanol atau etil alkohol. ${ }^{1,2}$

Produksi dan peredaran minuman keras yang diatur dalam Peraturan Menteri Kesehatan RI menyebutkan bahwa minuman keras adalah semua jenis minuman beralkohol tetapi bukan obat, meliputi minuman keras golongan $\mathrm{A}$ dengan kadar etanol 1\% sampai dengan $5 \%$, golongan $\mathrm{B}$ dengan kadar etanol 5\% sampai dengan $20 \%$ dan golongan C dengan kadar etanol lebih dari 20\% sampai dengan 55\%. ${ }^{3}$ Minuman keras ini telah beredar dan mudah didapat di Indonesia. Khususnya di Manado dapat dijumpai berbagai jenis minuman keras produk lokal, misalnya Cap Tikus.

Cap Tikus adalah jenis cairan dengan kadar alkohol rata-rata $40 \%$ yang dihasilkan melalui penyulingan saguer (cairan putih yang keluar dari mayang pohon enau atau seho dalam bahasa daerah Minahasa). Saguer sejak keluar dari mayang pohon enau sudah mengandung alkohol. Untuk mendapatkan saguer yang manis seperti gula, bambu penampungan digantungkan pada bagian mayang tempat keluarnya cairan putih (saguer) dan saringannya terbuat dari ijuk pohon enau yang bersih. Tinggi rendahnya kadar alkohol pada Cap Tikus tergantung pada kualitas penyulingan. Semakin bagus sistem penyulingannya, semakin tinggi pula kadar alkoholnya. ${ }^{4}$

Sistem reproduksi pria diatur oleh hipotalamus, kelenjar hipofisis anterior dan testis. Alkohol dapat mengganggu fungsi masing-masing komponen sehingga menyebabkan impotensi, infertilitas dan karakteristik seksual sekunder pria berkurang. Terlebih dahulu alkohol akan menyebabkan terganggunya Gonadotrophine Releasing Hormone (GnRH).
Selanjutnya di kelenjar hipofisis, alkohol dapat menurunkan pembentukan, pelepasan dan/atau kegiatan dari dua hormon yang berperan penting dalam fungsi reproduksi yaitu Luteinizing Hormone (LH) dan Follicle Stimulating Hormone (FSH). Sehingga di dalam testis, alkohol mempengaruhi sel-sel Leydig yang memproduksi dan mengeluarkan hormon testosteron. Alkohol juga mengganggu fungsi sel Sertoli di testis yang memainkan peran penting dalam pematangan sel spermatozoa. $^{5}$

Berdasarkan permasalahan diatas maka terdapat rumusan masalah yaitu, bagaimana pengaruh pemberian Cap Tikus terhadap kualitas spermatozoa wistar jantan (Rattus norvergicus)?. Tujuan dari penelitian ini adalah untuk mengetahui pengaruh pemberian Cap Tikus terhadap kualitas spermatozoa wistar jantan (Rattus norvegicus) yang meliputi konsentrasi, motilitas dan morfologi spermatozoa.

\section{METODE PENELITIAN}

Penelitian ini adalah eksperimental dengan rancangan acak lengkap (Completely randomized design). Penelitian dilakukan di Laboratorium Biologi Fakultas Kedokteran Universitas Sam Ratulangi Manado dengan rentang waktu Oktober-Desember 2014 selama 52 hari.

Penelitian ini menggunakan hewan coba wistar jantan (Ratus norvegicus) dengan kriteria inklusi yaitu wistar jantan (Rattus norvegicus) usia 5-6 bulan dengan berat badan 150-200 gram. Kriteria eksklusi yaitu wistar tampak sakit, tidak bergerak secara aktif dan wistar mati dalam penelitian.

Penelitian ini menggunakan 2 perlakuan. Selanjutnya secara acak wistar jantan dibagi menjadi 2 kelompok yaitu kelompok kontrol $\left(\mathrm{P}_{0}\right)$ yang terdiri dari 5 ekor wistar jantan tanpa diberi Cap Tikus dan kelompok perlakuan $\left(\mathrm{P}_{1}\right)$ yang terdiri dari 6 ekor tikus wistar jantan yang diberi Cap Tikus selama 52 hari dan diganti setelah 3 hari. Perlakuan akan mulai dilakukan setelah satu minggu hewan coba diaklimatisasi. Sebelum perlakuan, terlebih 
dahulu dilakukan pengenceran kadar alkohol pada Cap Tikus menjadi 20\%. Pengenceran tersebut menggunakan rumus: V1.C1 = V2.C2 dimana: V1 adalah volume yang dibutuhkan, C1 adalah konsentrasi yang dibutuhkan, V2 adalah volume yang tersedia dan C2 adalah konsentrasi yang tersedia.

Hewan diterminasi kemudian dibedah menggunakan disecting kit untuk mengambil epididimis. Selanjutnya epididimis dimasukkan ke dalam cawan petri yang berisi $1 \mathrm{ml} \mathrm{NaCl} \mathrm{0,9 \%} \mathrm{kemudian}$ epididimis dipotong-potong sampai halus dan diaduk agar tersuspensi dengan $\mathrm{NaCl}$ $0,9 \%$ sehingga terbentuk suspensi spermatozoa.

Konsentrasi spermatozoa dihitung menggunakan rumus: N/2 x 50.000 spermatozoa/ml, dimana $\mathrm{N}$ adalah jumlah total spermatozoa yang dihitung pada kotak A, B, C dan D. Preparat diamati dibawah mikroskop dengan pembesaran 400x.

Motilitas spermatozoa dihitung dengan melakukan pemeriksaan pada 3 lapangan pandang untuk mendapatkan 100 spermatozoa secara berurutan. Kategori motilitas spermatozoa terbagi menjadi 3 kategori, yaitu kategori A: gerakan spermatozoa maju lurus dan cepat (progresif), kategori B: gerakan spermatozoa bergerak di tempat (nonprogresif) dan kategori C: spermatozoa diam atau tidak bergerak. Motilitas spermatozoa dikatakan normal apabila jumlah dari kategori A dan kategori B adalah sebesar $40 \%$ atau lebih. Preparat diamati dibawah mikroskop dengan pembesaran 400x.

Morfologi spermatozoa diperiksa setelah membuat hapusan dan pewarnaan. Setelah itu, preparat mulai diamati dibawah mikroskop dengan pembesaran 400x untuk menghitung presentase morfologi spermatozoa normal dan abnormal.

\section{HASIL PENELITIAN \\ Konsentrasi spermatozoa}

Setelah dilakukan perlakuan pemberian Cap Tikus selama 52 hari dan penelitian terhadap konsentrasi spermatozoa tikus wistar jantan pada masing-masing kelompok maka didapatkan hasil seperti yang terlihat pada tabel 1 dibawah ini:

Tabel 1. Hasil perhitungan konsentrasi spermatozoa tikus wistar jantan setelah perlakukan pemberian Cap Tikus

\begin{tabular}{cc}
\hline $\begin{array}{c}\text { Kelompok } \\
\text { sampel }\end{array}$ & $\begin{array}{c}\text { Konsentrasi spermatozoa } \\
\left(\mathrm{x} 10^{6} \text { spermatozoa/ml) }\right.\end{array}$ \\
\hline Kontrol $\left(\mathrm{P}_{0}\right)$ & 59 \\
Perlakuan $\left(\mathrm{P}_{1}\right)$ & \\
Tikus 1 & 30 \\
Tikus 2 & 15 \\
Tikus 3 & 35 \\
Tikus 4 & 26 \\
Tikus 5 & 14 \\
\hline
\end{tabular}

Keterangan: Kelompok kontrol $\left(\mathrm{P}_{0}\right)$; Kelompok perlakuan $\left(\mathrm{P}_{1}\right)$ : tikus 1 dengan ratarata minuman $7,73 \mathrm{ml} /$ hari; tikus 2 dengan ratarata minuman 4,12 $\mathrm{ml} /$ hari; tikus 3 dengan ratarata minuman 11,8 $\mathrm{ml} /$ hari; tikus 4 dengan ratarata minuman $6,87 \mathrm{ml} / \mathrm{hari}$; tikus 5 dengan ratarata minuman $3,75 \mathrm{ml} /$ hari.

Rata-rata konsentrasi spermatozoa kelompok perlakuan adalah $24 \times 10^{6}$ spermatozoa/ml, sedangkan konsentrasi spermatozoa kelompok kontrol adalah $59 \times 10^{6} \quad$ spermatozoa $/ \mathrm{ml}$. Sehingga didapatkan hasil bahwa konsentrasi spermatozoa kelompok perlakuan mengalami penurunan jika dibandingkan dengan kelompok kontrol.

Setelah dilakukan perlakuan pemberian Cap Tikus selama 52 hari dan penelitian terhadap motilitas spermatozoa tikus wistar jantan pada masing-masing kelompok maka didapatkan hasil seperti yang terlihat pada Tabel 2.

Rata-rata presentase motilitas spermatozoa normal kelompok perlakuan adalah 23,5\%, sedangkan presentase motilitas spermatozoa normal kelompok kontrol adalah 89\%. Sehingga didapatkan hasil bahwa motilitas spermatozoa kelompok perlakuan mengalami penurunan jika dibandingkan dengan kelompok kontrol. 
Tabel 2. Hasil perhitungan motilitas spermatozoa tikus wistar jantan setelah perlakukan pemberian Cap Tikus

\begin{tabular}{cccc}
\hline & \multicolumn{3}{c}{ Motilitas spermatozoa (\%) } \\
Kelompok & \multicolumn{3}{c}{ Kategori } \\
sampel & A & B & C \\
\hline Kontrol ( $\left.\mathrm{P}_{0}\right)$ & 59 & 30 & 11 \\
Perlakuan ( $\left.\mathrm{P}_{1}\right)$ & & & \\
Tikus 1 & 0 & 34 & 66 \\
Tikus 2 & 0 & 19 & 81 \\
Tikus 3 & 11 & 28 & 61 \\
Tikus 4 & 0 & 15 & 85 \\
Tikus 5 & 0 & 11 & 89 \\
\hline
\end{tabular}

Keterangan: Kelompok kontrol $\left(\mathrm{P}_{0}\right)$; Kelompok perlakuan $\left(\mathrm{P}_{1}\right)$ : tikus 1 dengan ratarata minuman $7,73 \mathrm{ml} /$ hari; tikus 2 dengan ratarata minuman 4,12 ml/hari; tikus 3 dengan ratarata minuman 11,8 ml/hari; tikus 4 dengan ratarata minuman $6,87 \mathrm{ml} / \mathrm{hari}$; tikus 5 dengan ratarata minuman $3,75 \mathrm{ml} / \mathrm{hari}$.

Setelah dilakukan perlakuan pemberian Cap Tikus selama 52 hari dan penelitian terhadap morfologi spermatozoa tikus wistar jantan pada masing-masing kelompok maka didapatkan hasil seperti yang terlihat pada Tabel 3 dibawah ini:

Tabel 3. Hasil perhitungan morfologi spermatozoa tikus wistar jantan setelah perlakukan pemberian Cap Tikus.

\begin{tabular}{|c|c|c|}
\hline \multirow{2}{*}{$\begin{array}{l}\text { Kelompok } \\
\text { sampel }\end{array}$} & \multicolumn{2}{|c|}{$\begin{array}{c}\text { Morfologi } \\
\text { spermatozoa (\%) }\end{array}$} \\
\hline & Normal & Abnormal \\
\hline Kontrol $\left(\mathrm{P}_{0}\right)$ & 97 & 3 \\
\hline Perlakuan $\left(\mathrm{P}_{1}\right)$ & & \\
\hline Tikus 1 & 12 & 88 \\
\hline Tikus 2 & 7 & 93 \\
\hline Tikus 3 & 15 & 85 \\
\hline Tikus 4 & 8 & 92 \\
\hline Tikus 5 & 13 & 87 \\
\hline
\end{tabular}

Keterangan: Kelompok kontrol $\left(\mathrm{P}_{0}\right)$; Kelompok perlakuan $\left(\mathrm{P}_{1}\right)$ : tikus 1 dengan ratarata minuman 7,73 $\mathrm{ml} /$ hari; tikus 2 dengan rata- rata minuman 4,12 $\mathrm{ml} /$ hari; tikus 3 dengan ratarata minuman 11,8 $\mathrm{ml} / \mathrm{hari}$; tikus 4 dengan ratarata minuman $6,87 \mathrm{ml} /$ hari; tikus 5 dengan ratarata minuman $3,75 \mathrm{ml} /$ hari.

Rata-rata persentase morfologi spermatozoa normal kelompok perlakuan adalah 11\%, sedangkan presentase morfologi spermatozoa normal kelompok kontrol adalah 97\%. Sehingga didapatkan hasil bahwa morfologi spermatozoa kelompok perlakuan mengalami penurunan jika dibandingkan dengan kelompok kontrol.

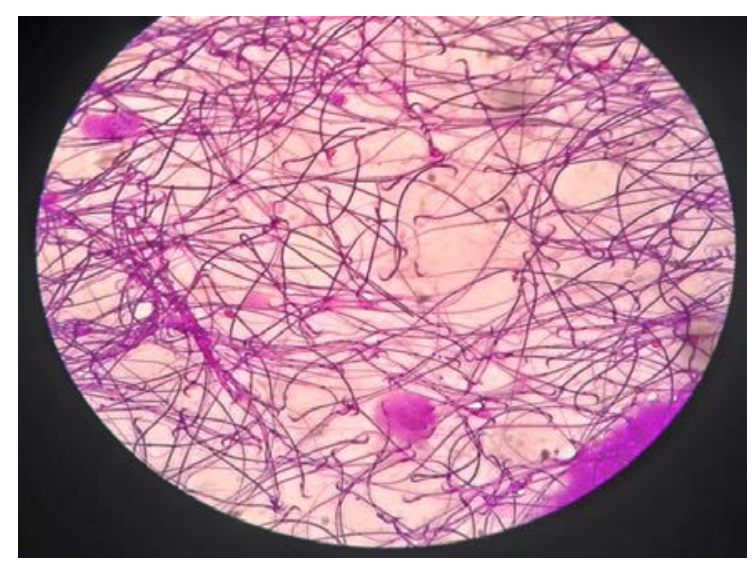

Gambar 1. Spermatozoa wistar kontrol

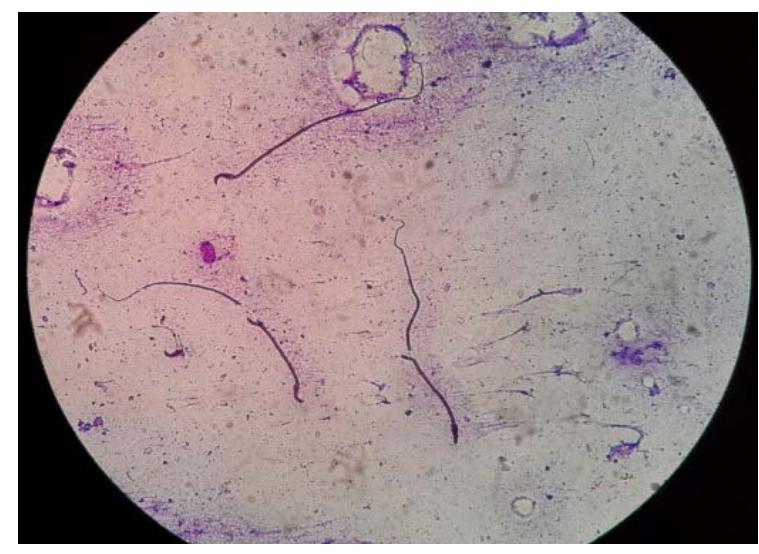

\section{Gambar 2. Spermatozoa wistar perlakuan (tikus 5)}

Pada penelitian ini morfologi abnormal spermatozoa yang ditemukan adalah spermatozoa wistar dengan kepala yang lurus, ekor yang putus dan berkerut. Yang paling banyak ditemukan pada penelitian ini adalah spermatozoa wistar yang terlihat pada Gambar 2. 


\section{BAHASAN}

\section{Konsentrasi spermatozoa}

Pada penelitian ni didapatkan hasil yang menunjukkan bahwa rata-rata konsentrasi spermatozoa wistar jantan (Rattus norvegicus) setelah diberi perlakuan dengan pemberian Cap Tikus selama 52 hari mengalami penurunan. Kelompok kontrol $\left(\mathrm{P}_{0}\right)$ yang tidak diberi Cap Tikus menunjukkan rata-rata yang lebih tinggi dibandingkan dengan kelompok perlakuan $\left(\mathrm{P}_{1}\right)$. Ini menunjukkan bahwa pemberian Cap Tikus menurunkan konsentrasi spermatozoa.

Penurunan konsentrasi spermatozoa ini diakibatkan oleh alkohol yang mengganggu hipotalamus dalam memproduksi $\mathrm{GnRH}$ sehingga dua jenis gonadrotropin yaitu LH dan FSH juga akan terganggu. Hal ini akan mengganggu spermatogenesis tikus wistar jantan. ${ }^{5} \quad$ Rusaknya sel-sel Sertoli mengakibatkan gangguan pada proses mitosis dan meiosis (spermatocytogenesis) maupun proses pembentukan spermatozoa (spermio-genesis) sedangkan rusaknya selsel Leydig menyebabkan gangguan pada proses sintesis hormon testosteron yang mengakibatkan penurunan kadar hormon testosteron, dimana penurunan hormon testosteron ini akan mengganggu proses spermatogenesis dan menyebabkan penurunan jumlah lapisan sel spermatogenik. ${ }^{5,6}$

\section{Motilitas spermatozoa}

Pada penelitian ini didapatkan hasil yang menunjukkan bahwa rata-rata motilitas spermatozoa wistar jantan (Rattus norvegicus) setelah diberi perlakuan dengan pemberian Cap Tikus selama 52 hari mengalami penurunan yang sangat nyata. Kelompok kontrol yang tidak diberi Cap Tikus menunjukkan rata-rata motilitas yang lebih tinggi dibandingkan dengan kelompok perlakuan. Motilitas pada kelompok kontrol termasuk normal sedangkan pada kelompok perlakuan, motilitas semua tikus wistar jantan mengalami penurunan. Selain itu dapat diamati bahwa, semakin sedikit yang diminum maka semakin menurun presentase motilitas spermatozoa.

Penurunan jumlah motilitas spermatozoa berkaitan erat dengan peningkatan presentase yang mengalami kelainan morfologi. ${ }^{7}$ Penurunan ini menunjukkan adanya gangguan pematangan spermatozoa pada duktus epididimis karena ikut berperannya prostaglandin F2 $\alpha$ (PGF2 $\alpha$ ) dalam proses glikolisis maupun dalam mengontrol proses degradasi asam lemak selama masa pematangan spermatozoa sehingga banyak spermatozoa yang hanya bergerak di tempat dan tidak bergerak sama sekali yang dikategorikan dalam kategori B dan C.,8 PGF2 $\alpha$ merupakan suatu agen yang menyebabkan regresi korpus luteum dan berperan dalam mengontrol siklus estrus, kelahiran, transportasi ovum dan spermatozoa. $^{9}$

\section{Morfologi spermatozoa}

Pada penelitian ini didapatkan hasil analisis yang menunjukkan bahwa rata-rata morfologi spermatozoa wistar jantan (Rattus norvegicus) setelah diberi perlakuan dengan pemberian Cap Tikus selama 52 hari mengalami penurunan. Kelompok kontrol yang tidak diberi Cap Tikus menunjukkan rata-rata morfologi yang lebih normal dibandingkan dengan kelompok perlakuan. Sedangkan pada kelompok perlakuan, morfologi wistar jantan mengalami penurunan. Dimana terdapat kepala yang lurus, kepala yang bercabang, ekor yang patah, ekor yang tidak lurus atau berkelok-kelok.

Abnormalitas morfologi spermatozoa disebabkan karena adanya gangguan pematangan spermatozoa dan gangguan pada proses sintesis hormon sehingga menyebabkan gangguan pada proses pembentukan spermatozoa dimana dengan adanya kelainan morfologi tersebut juga akan berpengaruh terhadap motilitas spermatozoa. ${ }^{5,7}$ Selain itu abnormalitas ini juga disebabkan oleh gangguan peningkatan tonus yang mempengaruhi kekuatan kontraksi otot polos yang terdapat disepanjang duktus epididimis. ${ }^{8}$ 


\section{SIMPULAN DAN SARAN}

Berdasarkan hasil penelitian dan pembahasan dapat diambilkan kesimulan bahwa pemberian Cap Tikus menyebabkan penurunan kualitas spermatozoa secara nyata yang meliputi konsentrasi, motilitas dan morfologi spermatozoa. Semakin sedikit pemberian Cap Tikus, maka semakin menurun berat badan tikus wistar jantan dan menyebabkan penurunan kualitas spermatozoa. Cap Tikus menyebabkan penurunan kualitas spermatozoa karena alkohol menganggu kerja daripada hipotalamus dan hipofisis anterior yang berperan dalam proses spermatogenesis.

Saran dari penelitian ini adalah perlu diinformasikan kepada masyarakat mengenai pemberian Cap Tikus yang dapat berpengaruh terhadap penurunan kualitas spermatozoa. Selain itu juga perlu dilakukan penelitian lebih lanjut mengenai kandungan Cap Tikus yang paling mempengaruhi penurunan kualitas spermatozoa.

\section{DAFTAR PUSTAKA}

1. Damin S. Pengantar kimia buku panduan kuliah mahasiswa kedokteran. Editor, Amalia Hanif, Juli Manurung, Jojor simanjuntak. Jakarta: EGC; 2009. p. 255

2. Hartono. Kemenperin Terbitkan Regulasi Bagi Industri Minuman Beralkohol. 2014 [cited 2014 October 10]. Available from: http://www.kemenperin.go.id/artikel/ 9705/Kemenperin-Terbitkan-
Regulasi-Bagi-Industri-Minuman-

Beralkohol

3. Menteri Perdagangan Republik Indonesia. Pengendalian dan pengawasan terhadap pengadaan, perderan dan penjualan minuman beralkohol. 2014 [cited 2014 Oktober 15]. Available from:

http://www.kemendag.go.id/files/regu lasi/2014/04/11/20m-dagper42014-id 1398307202.pdf

4. Makan dan minuman khas minahasa. c2004 [updated 2007 June 4, cited 2014 December 4]. Available from: http://www.theminahasa.net/social/tra dition/food/indexid.html

5. Emannuele M, Emanuele N. Alcohol's effect on male reproduction. Volume 22. National Institute of Alcohol Abuse and Alcoholism. 1998;22:195201.

6. Nugroho CA. Pengaruh minuman beralkohol terhadap jumlah lapisan sel spermatogenik dan berat vesikula seminalis mencit. [Skripsi]. Madiun. Universitas Widya Mandala Madiun; 2007.

7. Pengaruh Prostaglandin F2 $\alpha$ Terhadap Fertilitas Tikus (Rattus norvegicus) Wistar Jantan. Suripto, Sutasurya, Lien A., Hasanuddin, dan Adi, Dwi Arianto. JMS. 2000;5:69-81.

8. Tso EC, Lacy D. Effect of prostaglandin F $2 \alpha$ on the reproduction system of male rat. J. Reprod. Dert. 1975;44:545-50.

9. Pemayun O. Kadar prostaglandin F2 $\alpha$ pada cairan vesikula seminalis dan produk sel monolayer vesikula seminalis sapi bali. 2007;8:167-172. 